\title{
NUEVAS INSCRIPCIONES ÁRABES DE LA PROVINCIA DE JAÉN: LAS LÁPIDAS DE CAZALILLA Y DE ÚBEDA
}

\author{
Francisco Javier Aguirre Sádaba \\ Universidad de Jaén
}

A la memoria de Manuel Ocaña Jiménez

\section{INTRODUCCIÓN}

Las inscripciones andalusíes procedentes de la provincia de Jaén de las que se tiene conocimiento hasta la fecha sobrepasan la cifra de veinte piezas, hallándose distribuidas prácticamente en su totalidad entre el Museo Arqueológico Nacional de Madrid, el Museo Arqueológico de Córdoba y el Museo Provincial de Jaén, salvo un reducido número de ellas que se encuentran depositadas en colecciones privadas o bien en dependencias de las administraciones locales. A los inventarios realizados en el año 1931 por E. Lévi-Provençal, que en su estudio sobre las inscripciones árabes de España recoge doce de ellas procedentes de Jaén ${ }^{1}$, y más recientemente, en 1990 , por A. Labarta ${ }^{2}$, hay que añadir algunas inscripciones aisladas estudiadas por M. Ocaña Jiménez ${ }^{3}$ y A. Fernández Puertas ${ }^{4}$. Merced a estos trabajos, podemos contar en la actualidad con un material epigráfico que ya va siendo importante, al menos en términos numéricos, susceptible de proporcionar una información que puede permitir la anticipación de algunas conclusiones de carácter general sobre la epigrafía árabe en Jaén.

Con el objeto de aportar nuevos datos a la información disponible sobre el tema, voy a presentar aquí el estudio de dos documentos epigráficos originales: dos lápidas andalusíes que contienen sendas inscripciones funerarias y que proceden, respectivamente, de Cazalilla y de Úbeda.

1 Inscriptions arabes d'Espagne, Leiden-París, 193, I, 132-142.

2 "Las lápidas árabes de la provincia de Jaén», Homenaje a Manuel Ocaña Jiménez, Córdoba, 1990, 123-137.

3 "Un epitafio musulmán de Jimena (Jaén)", Al-Andalus, XVIII (1953), 400-401.

4 "Dos lápidas aparecidas en la provincia de Jaén", Al-Andalus, XLI (1976), 213 224. 
La primera de ellas está inédita y fue hallada en el año 1983 en Cazalilla, en uno de los cantones del antiguo camino de la Virgen de la Cruz, al efectuarse las obras para abrir la calle del mismo nombre, y desde entonces se encuentra depositada en la Casa Consistorial de dicha localidad giennense, donde he tenido oportunidad de examinarla ${ }^{5}$. De la segunda, la lápida de Úbeda, ya se tenía noticia porque en el año 1973 había sido reproducida fotográficamente en un tríptico informativo sobre el Museo de Úbeda, editado por la Dirección General de Bellas Artes, y unos años después A. Labarta la recogió en su relación ${ }^{6}$, ofreciendo una breve referencia acerca de su contenido. De acuerdo con los datos incluidos en la correspondiente ficha que existe en el Museo de Úbeda y con la información recabada de su director ${ }^{7}$, esta inscripción fue encontrada extramuros de Úbeda, al procederse a la realización de unas obras en una casa contigua a la muralla, y en el año 1971, aproximadamente, se entregó al Museo donde en la actualidad está depositada con el número 310 del inventario.

\section{Inscripción de Cazalilla (lám. I)}

\section{a) Descripción}

Se trata de una placa de piedra arenisca, de dimensiones irregulares y forma trapezoidal, que contiene el epitafio de Ahmad b. Mauro (Mawrū) (?). Está fechada, con omisión de la feria de la semana y el día, en el mes de $\check{s} a^{c} b a \bar{n} n$ del año 271 (=22 enero-19 febrero del año 885), lo que la acredita como la inscripción árabe más antigua de las que se han hallado en la provincia de Jaén. La lápida está completa y en buen estado de conservación, y no muestra fracturas ni grietas, salvo algunas muescas ocasionadas por las circunstancias de su descubrimiento que no afectan al texto de la inscripción, el cual tampoco aparece demasiado gastado y se percibe con suficiente nitidez. Presenta en su pie un perfil abiselado, de derecha a izquierda, que parece haber sido hecho a

\footnotetext{
5 Desde estas páginas quiero expresar mi agradecimiento al anterior alcalde de Cazalilla, don Juan Zarrías Jareño, por las facilidades ofrecidas para el estudio de la inscripción.

6 Op. cit., núm. 2, 126-127.

7 Don José Luis Latorre Bonachera, a quien agradezco la atención de haberme proporcionado unas fotografías de la inscripción.
} 
propósito por el tallista para facilitar la fijación de la losa en la tierra y que permaneciera firme en posición vertical, conforme al modelo de las estelas "cabeceras».

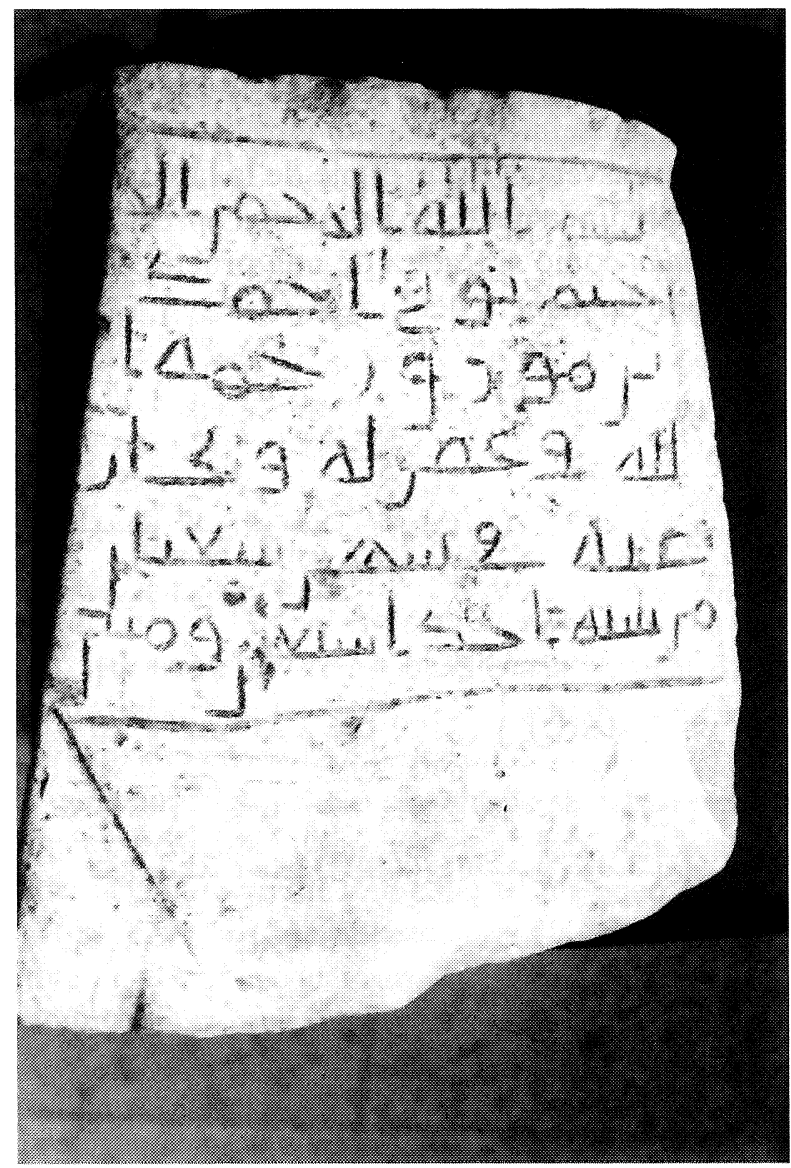

Lámina I.-Lápida árabe de Cazalilla

Las dimensiones de la placa, empezando por el lado superior y continuando por el derecho, son: 23, 29, 28 -en su parte más ancha-y $35 \mathrm{~cm}$, respectivamente, con $4 \mathrm{~cm}$ de grosor. El campo epigráfico mide $22,19,26$ y $21 \mathrm{~cm}$, y está ocupado por un texto completo que se desarrolla a lo largo de seis líneas de escritura incisa en cúfico arcaico. Como único elemento decorativo, el texto aparece enmarcado, en casi 
todo el perímetro del campo epigráfico, por una estrecha orla incisa, apenas un poco más ancha que los caracteres de la escritura, que fue trazada después de hacer la inscripción. Esto explica que, al no haber ajustado el tallista las palabras del texto adecuadamente a las dimensiones de la piedra, el lado izquierdo de la orla aparezca incompleto, cincelado en el canto izquierdo de la losa y no en la superficie frontal. La orla se cierra en la parte inferior con un giro brusco de izquierda a derecha, en sentido transversal, hacia el pie de la lápida. Entre el reborde superior y la primera línea del texto se pueden apreciar las palabras iniciales de la basmala, como si tratara de una prueba efectuada antes de trazar la inscripción de manera definitiva.

b) Lectura

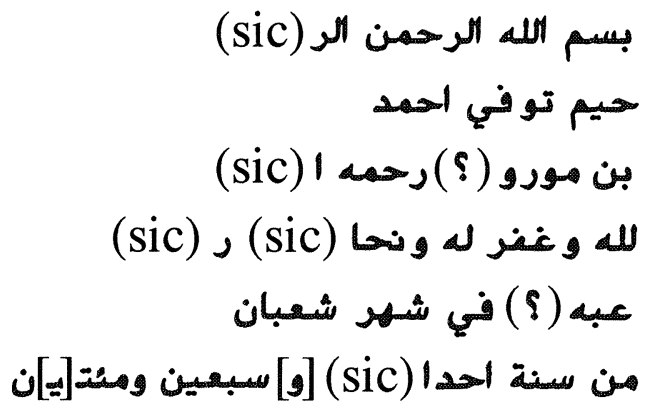

c) Traducción

«En el nombre de Dios, Clemente y Misericordioso. / Murió Ahmad / b. Mauro (Mawrū) (?), Dios tenga piedad de él, / le perdone y aparte / su temor (?), en el mes de $\check{s}^{c} b \bar{a} n$ / del año doscientos setenta y uno (=22 enero-19 febrero, del año 885).»

\section{d) Alifato}

La escritura de esta lápida presenta unos caracteres bastante simples, reduciéndose a trazos incisos toscamente labrados, con predominio de los perfiles rectos sobre los curvilíneos, poco proporcionados y de anchura similar en casi todos los casos, sin que pueda resaltarse en ella ningún rasgo de elegancia. He aquí la descripción de sus grafías (fig. I): 


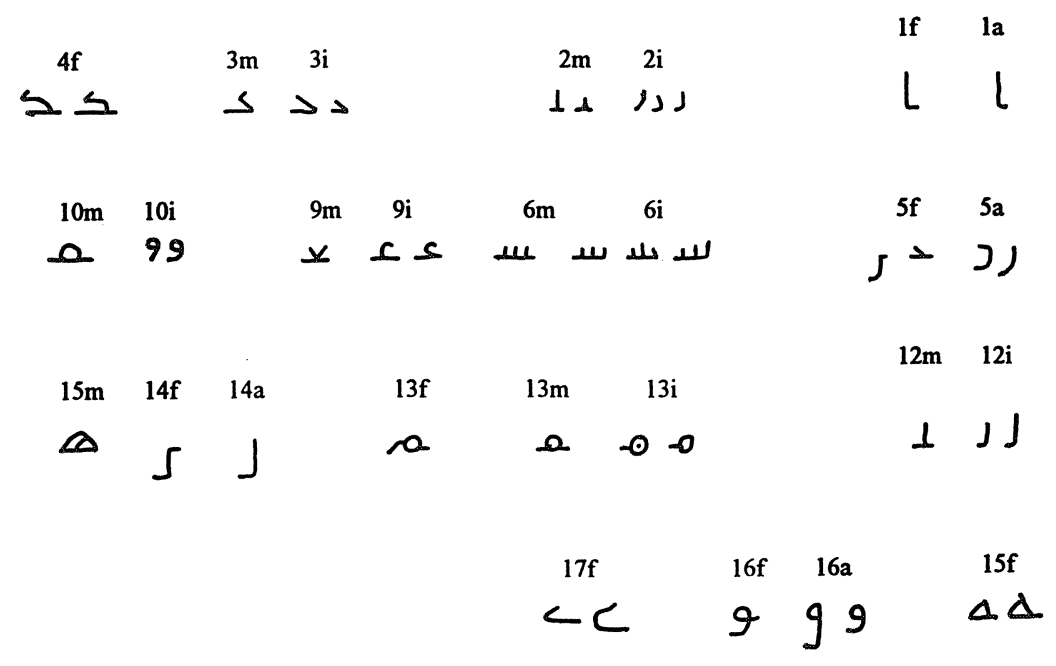

Figura I.-Alifato de la lápida de Cazalilla

La letra "alif» (núm. 1) aparece siete veces en forma aislada y dos en forma final, y consiste en una simple estría vertical. La inicial presenta en todos los casos un trazo corto hacia la derecha en su base. La ligación se ha realizado en sentido horizontal.

Las letras que configuran el segundo grupo se hallan representadas en sus formas inicial y medial, sin diferencias apreciables en la altura de su trazado, aunque en alguna ocasión la medial es un poco más alta. En casi todos los casos las ligaduras son horizontales. La forma inicial, unida a la $3 \mathrm{~m}$ en la palabra $n a h h a ̀$, ofrece una variedad consistente en un vástago muy corto, con ligadura oblicua, que aparece montado sobre la letra siguiente.

De las letras del grupo tercero sólo se emplea la «hä»", que aparece cinco veces en posición inicial y una en posición medial. En todos los casos, el cuerpo de la letra consiste en un trazo oblicuo, de longitud desigual, que se une a la línea de la base formando un ángulo agudo. La forma medial presenta la ligadura anterior en sentido oblicuo ascendente y la posterior en sentido horizontal. En la forma inicial la ligadura siempre aparece en sentido horizontal.

El grupo cuarto se encuentra representado dos veces y ambas en posición final. El cuerpo de la letra está formado por dos estrías paralelas, de diferente longitud, unidas en un caso por un trazo oblicuo y en el otro por un trazo curvilíneo. La estría superior presenta un apéndice oblicuo ascendente. La ligación es horizontal. 
El grupo quinto se presenta en las posiciones aislada y final. En la primera aparece de dos maneras: bien como un trazo curvilíneo descendente que se inicia por encima de la línea de escritura, bien en forma de semicírculo abierto hacia la izquierda, como en el nombre Mawrū. En la segunda posición también ofrece dos grafías diferentes: cuando se encuentra en medio de palabra, se hace uniendo un corto trazo oblicuo a otro horizontal, igualmente breve, formando un ángulo; a final de palabra adopta el aspecto de una curva descendente a partir de la línea de escritura. El trazo descendente forma un ángulo recto en la palabra šahr. La ligación es siempre horizontal.

El grupo sexto aparece en las formas inicial y medial, con los vástagos verticales trazados en altura decreciente de derecha a izquierda, iguales o sobresaliendo el del centro, y con las ligaduras horizontales.

Las letras del grupo noveno aparecen en posición inicial y medial. En la primera, el cuerpo de la letra forma un semicírculo abierto hacia la derecha, cuyo trazo inferior se prolonga hacia abajo para alcanzar la línea horizontal, o bien un gancho con una base horizontal de mayor longitud, como en la expresión $r u^{e} b a-h u$. En posición medial adopta el aspecto de una /v/. La ligación es horizontal.

El grupo diez está presente en dos ocasiones en posición inicial y una en posición medial. En la primera de las posiciones tiene forma circular y aparece seguido de $17 \mathrm{f}$ en los dos casos, pero en uno la ligación es horizontal y en el otro es oblicua ascendente. En posición medial el cuerpo de la letra tiene forma ovalada y la ligación es horizontal.

La letra «läm» (núm. 12), representada por un sencillo trazo vertical, aparece en posición inicial y medial. Cuando es inicial tiene la misma altura que $1 a$, menos en la palabra Allāh, en la que también puede apreciarse la menor altura de la forma medial, de manera que en dicho vocablo los tres trazos verticales aparecen en altura decreciente de derecha a izquierda.

La "mim» (núm. 13) se representa en posición inicial, medial y final, y tiene forma de círculo, a veces con un punto en el centro. La grafía final lleva un corto apéndice que se inicia con un trazo horizontal para continuar de forma oblicua descendente. Las ligaduras son horizontales y en posición inicial salen a media altura del cuerpo de la letra, mientras que en posición medial y final lo hacen casi desde la base de la misma.

La «nūn» aislada y la final (núm. 14) se reducen a un largo trazo vertical descendente, que a veces se inicia por encima de la línea de es- 
critura y termina con un trazo horizontal más corto, hacia la izquierda, formando ángulo recto. La ligación es horizontal.

El grupo quince aparece en sus formas medial y final. En ambos casos ofrece un aspecto triangular, con base más larga en posición medial en la que, además, presenta un vástago oblicuo que sale desde el centro de la base hasta tocar el lado derecho, y tiene el vértice superior ligeramente redondeado. Las ligaduras son horizontales.

La «wāu» (núm. 16) se encuentra en posición aislada y final, y presenta un cuerpo ovalado por arriba y aplanado en su parte interior, con un apéndice que se curva formando un trazo paralelo al cuerpo de la letra. En el nombre Mawrū la forma aislada presenta un desarrollo vertical más acentuado que en los demás casos. La ligación es horizontal.

La "yāi final (núm. 17) ofrece una grafía diferente en cada una de las dos ocasiones en las que aparece, precedida en ambas de 10i. En un caso forma una curva suave, descendiendo por debajo de la línea de escritura, mientras que en el otro se inicia con un vástago corto para girar bruscamente a la derecha en un trazo horizontal que sigue la línea de escritura. La ligación es oblicua descendente.

\section{e) Comentario epigráfico}

La estructura del texto se ajusta a la forma más sencilla de composición que pueden adoptar los epitafios funerarios andalusíes ${ }^{8}$, de acuerdo con el siguiente esquema:

Fórmula de inauguración

Identidad del difunto

Eulogia

Fecha

Se inicia con la basmala como fórmula de inauguración y a continuación se indica el nombre del difunto, enunciado por el ism y un $n a$ $s a b$ de un solo elemento, precedido de la expresión tuwuffiya; sigue una triple eulogia y concluye con la consignación de la fecha del óbito, empleándose la palabra sana, sin señalar la feria semanal ni el día del mes.

8 Véase Lévi-Provençal, E., op. cit., XXI; Barceló, C., "Estructura textual de los epitafios andalusíes (siglos IX-XIII)", Homenaje a Manuel Ocaña Jiménez, 41-54, en particular, 44-50. 
Dentro de los rasgos comunes a otros epitafios andalusíes, y en concreto a los de Jaén, que esta lápida presenta, me parece interesante destacar como elemento diferenciador dos de las tres fórmulas de eulogia utilizadas después de la mención del nombre del difunto. Así, junto a la generalizada expresión rahima-hu Alläh (Dios tenga piedad de él), aquí se han incluido dos fórmulas no utilizadas en Jaén, y una de ellas, además, nada habitual en los epígrafes funerarios andalusíes, según la información de que dispongo. La primera es la fórmula wa-gafara la-hu ([Dios] le conceda el perdón) que figura ya en una lápida sepulcral cordobesa datable en el año 233 (848) ó $236(851){ }^{9}$ y se repite luego en otras, pero que no se encuentra hasta ahora en ninguno de los epitafios procedentes de Jaén. La otra fórmula es wa-nahhà $r u^{c} b a-h u$ (y aparte su temor) y no la he encontrado utilizada en ninguna de las lápidas que han sido estudiadas. La lectura es conjetural, pero la grafía del texto no permite una interpretación que se acomode a cualquier otra fórmula más convencional de eulogia.

Entre las irregularidades ortográficas que el texto presenta, además del uso de "alif țawila" por "alif maqșūra" en iḥdà y nahhhà, se pueden advertir las habituales incorrecciones en el remate de las líneas de escritura, con la separación de las letras en las palabras rahim, Allāh y $r u^{\mathrm{c}} b a$, en las líneas $1 .^{\mathrm{a}}, 3 .^{\mathrm{a}}$ y $4 .^{\mathrm{a}}$ respectivamente. Asimismo, en la anotación de la fecha que aparece en la línea $6{ }^{\mathrm{a}}$ se aprecian dos omisiones: la partícula $w a$ entre las unidades y las decenas, y la "y $y \vec{a}$ " medial en la desinencia del dual en el numeral de las centenas.

En la indicación de la identidad del fallecido se lee el antropónimo «Mauro» o «Moro» (Mawrū, Mūrū), apelativo de raíz latina ${ }^{10}$ que sugiere un probable origen muladí del personaje. Tenemos constancia del empleo de este nombre en al-Andalus, a través de los datos biográficos recogidos por Ibn al-Abbār acerca de un almocrí de Guadalajara del siglo XI, llamado Abū 'Umar Aḥmad b. Muhammad y conocido por Ibn al-Mawruh (o al-Mūruh) ${ }^{11}$. Observaremos que, mientras que en el nombre de este personaje citado por Ibn al-Abbār la terminación /o/

9 Ocaña Jiménez, M., El cúfico hispano y su evolución, Madrid, 1970, lám. III.

10 Simonet, F. J., Glosario de voces ibéricas y latinas usadas entre los mozárabes, precedido de un estudio sobre el dialecto hispano-mozárabe, Madrid, 1888, 354; Egger, C., Lexicon nominanum virorum et mulierum, Roma, 1963, p. 165.

11 Al-Takmila li-Kitäb al-Ṣila, ed. A. Bel y M. Ben Cheneb, Alger, 1920, núm. 55, pp. 29-30. Cfr. Marín, M., «Ulemas en la Marca Media», Estudios Onomástico-Biográficos de al-Andalus, VII (Madrid, 1995), 203-229. 
de los nombres hispano-latinos se conserva por medio de la incorporación de una $/ h /$, en el texto de la inscripción se ha mantenido a través de la adición de una / $w /$, lo que tampoco es infrecuente según ya señalara F. J. Simonet ${ }^{12}$.

Como conclusión de estos aspectos de la inscripción que vengo comentando, puede decirse que nos hallamos ante un interesante ejemplar de epitafio rural andalusí, en el que se evidencian los rasgos de tosquedad, incuria y sencillez en la talla, la grafía y la estructura textual, característicos de este tipo de inscripciones.

\section{f) Comentario histórico}

Aparte de los datos que se desprenden de la lectura de la inscripción y de las circunstancias de su hallazgo, ninguna otra información ha sido posible recabar sobre este desconocido personaje llamado Ahmad b. Mauro. Como antes apuntaba, el nasab Ibn Mauro puede aludir a su posible origen muladí. La fecha de su muerte (año 271/885) señala que vivió durante el gobierno del emir Muḥammad I (852-886), llegando a conocer los comienzos de la crisis del emirato y las luchas civiles que se produjeron a finales del siglo ix en el sur de al-Andalus, en las que los muladíes de las zonas rurales tuvieron un protagonismo destacado, particularmente en la cora de Jaén. Es probable, asimismo, que fuera vecino de la localidad a cuyas afueras recibió sepultura.

Cazalilla ha sido identificada con la población que en las fuentes árabes recibe el nombre de Qastallat Darrāŷy y también Qastallat.Mar$w \bar{a}{ }^{13}$, cabeza de distrito en la Cora de Jaén y lugar de nacimiento del célebre poeta hispanomusulmán de origen beréber Ahmad b. Darrāŷ al-Qastallī (958-1030) ${ }^{14}$. No es éste el momento de abordar la cuestión de la correspondencia de este topónimo. Sin embargo, conviene señalar que lo común de su denominación -del árabe dialectal qastalla o qaștalla ("castaño, castaña») ${ }^{15}$ - explica la coincidencia de otros luga-

12 Op. cit., p. CXXVIII.

13 Véase al-Marrākušì, Al-Dayl wa-l-takmila li-kitābay al-Mawșūl wa-l-Ṣila, IV(2), ed. Iḥsān 'Abbās, Beirut, s.d., p. 178, núm. 322.

14 Makkī, M. 'A., "Ibn Darrādj al-Kastallī», $E l^{2}$, III, 765-767 (s.v.). Sobre Oastallat Darrāŷ, véase Aguirre Sádaba F. J., y Jiménez Mata, M. C., Introducción al Jaén Islámico, Jaén, 1979, 33, 53, 63 y 130; Aguirre Sádaba, F. J., «El Jaén islámico», Historia de Jaén Jaén, 1982, 179 y 190

15 Véase Oliver Asín, J., "En torno a los orígenes de Castilla", Al-Andalus, XXXVIII (1973), 362. 
res dispersos por la geografía peninsular, y también en la provincia de Jaén -verbigracia Cazalla, cerca de Carchelejo-, que llevan nombres cuya etimología puede relacionarse con aquél. Así sucede con Cacela, pequeña localidad portuguesa del Algarve próxima a Tavira, que también ha sido identificada como la patria chica de Ibn Darrāŷ pero que, seguramente, corresponde a la Qastallat al-garb citada por Ibn Bassām ${ }^{16}$. En todo caso, este sencillo pero interesante documento epigráfico constituye el testimonio más antiguo conocido hasta ahora sobre Cazalilla en época musulmana, y no deja dudas acerca de su existencia como entidad de población en aquel tiempo.

\section{Inscripción de Úbeda (lám. II)}

\section{a) Descripción}

Esta segunda lápida es una estela de piedra arenisca rojiza, de forma rectangular, con una inscripción completa en ocho líneas de escritura incisa en cúfico arcaico que comienzan a una distancia de $17,5 \mathrm{~cm}$ del borde superior y sobrepasan la mitad de la losa, y que no presenta ningún rasgo ornamental. Contiene el epitafio de Abū l-'Abbās Ibn 'Abd al-Malik b. 'Umar y lleva fecha del mes de raŷab del año $361 \quad(=18$ de abril a 17 de mayo del 972) ${ }^{17}$, sin consignación del día ni de la feria semanal de la misma forma que sucede en la inscripción anterior. Sus dimensiones máximas son $84 \times 33 \mathrm{~cm}$ y $5 \mathrm{~cm}$ de grosor; la caja del texto ocupa un espacio de $27 \times 31,5 \mathrm{~cm}$.

Aunque está partida por la mitad y se aprecia la pérdida de dos fragmentos pequeños, uno en cada lateral de la losa, su estado de conservación es aceptable. Estas imperfecciones afectan al comienzo de la línea quinta del texto y a la línea sexta en su totalidad, impidiendo su lectura e interpretación. Los perfiles irregulares de la lápida evidencian la precaria labor de preparación de la misma antes de realizar la inscripción. Su pie tiene también forma abiselada, quizá con la misma finalidad que se ha sugerido más arriba para la inscripción de Cazalilla.

${ }^{6}$ Al-Dajīra fì mahäsin ahl al-Ŷyazira, ed. I. 'Abbās, Beirut, 1979, III (1), 336.

17 En la noticia que A. Labarta ofreció de esta lápida, interpretó la data anual que en ella aparece como el año 3[3]1/943, sin mencionar el nombre del mes. 


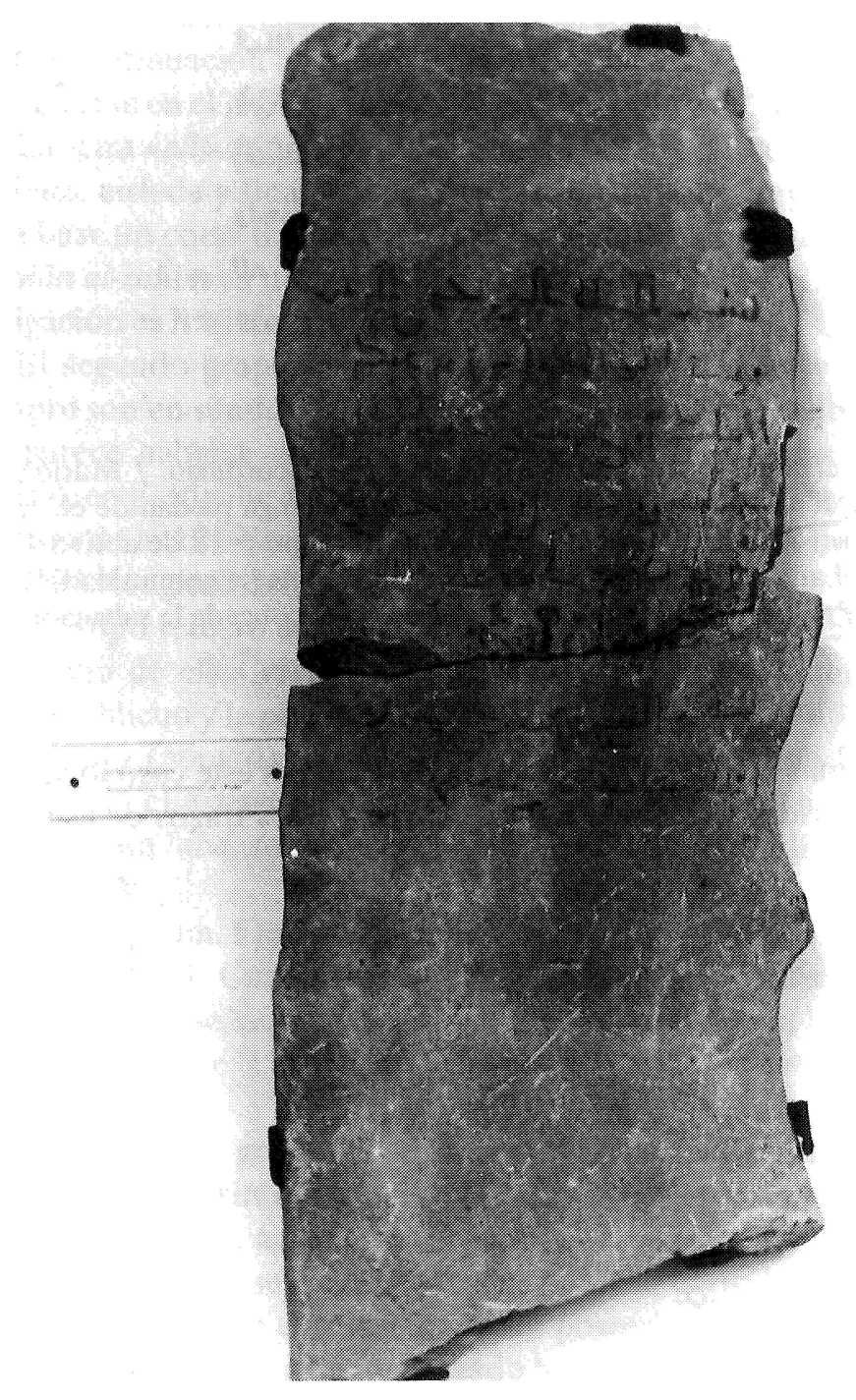

Lámina II.-Lápida árabe del Museo de Úbeda 
b) Lectura

$$
\begin{aligned}
& \text { بهسم الله الوحمن الوحم (sic) } \\
& \text { تو في ابو العباس ابن عبد التبد }
\end{aligned}
$$

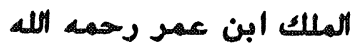

$$
\begin{aligned}
& \text { في شيهر رجب مين سنة الهد(sic)و و(sic) }
\end{aligned}
$$

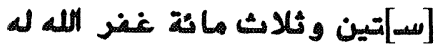

$$
\begin{aligned}
& \text { [1] } \\
& \text { لله بالنبي مجمد صلا (sic) } \\
& \text { الله عليه و سلما (sic) }
\end{aligned}
$$

c) Traducción

«En el nombre de Dios, Clemente y Misericordioso. / Murió Abū l-Abbās Ibn 'Abd / al-Malik ibn 'Umar, Dios tenga piedad de él, /en el mes de raŷab del año / trescientos [sese]nta y uno (=18 de abril a $17 \mathrm{de}$ mayo del año 972). Dios le perdone / y perdone a [la comunidad]? (...) / Dios el Profeta Muhammad, Él le bendiga / y le conceda la salvación.»

d) Alifato

Aún con más razón, podemos hacer extensivo a este caso lo señalado con anterioridad acerca de la simplicidad de los trazos de escritura

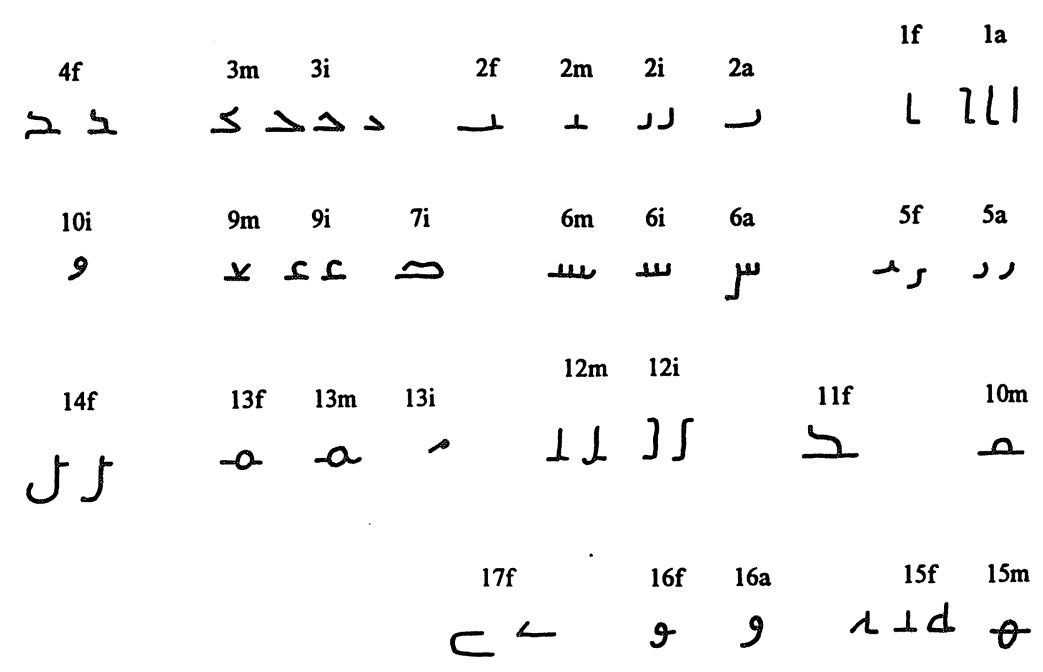

Figura II.-Alifato de la lápida del Museo de Úbeda 
de la lápida de Cazalilla. Los signos de esta inscripción han sido labrados de forma tan rudimentaria que más bien parece tratarse de grafitos. En algunos casos, como en el vocablo sallà, las ligaduras no se perciben, y en otros el trazado de la letra aparece muy esquematizado. Procedo a continuación a realizar el estudio de los caracteres, cuyo dibujo puede verse en el gráfico adjunto (fig. II).

La letra "alif» (núm. 1) está presente en el texto en sus dos formas posibles, aislada y final. Cuando es aislada alcanza mayor altura y lleva en la base un corto trazo de retorno hacia la derecha; en las palabras alrahmān al-rahim va unida por el extremo superior a la $12 \mathrm{i}$ que le sigue. La ligación es horizontal.

El segundo grupo aparece en todas las posiciones y sus ligaduras siempre son en sentido horizontal, si bien en el caso del nombre al- ${ }^{-} \mathrm{Ab}-$ bās parece haberse omitido. La forma inicial tiene mayor desarrollo vertical, en particular en la $2 \mathrm{i}$ que comienza la basmala, pero sin llegar a la altura de la 12i. En posición final termina en un trazo horizontal que duplica la longitud del pedículo de la letra.

El grupo tercero se halla en las formas inicial y medial, ofreciendo la primera de ellas variedad de tamaño. La ligadura anterior tiene un trazado oblicuo y la posterior horizontal.

$\mathrm{El}$ «dāb) (núm. 4) se encuentra en posición final con forma de /u/ tendida. En el extremo del trazo superior, y también en el del inferior en la palabra ' $a b d$, sobresale un apéndice oblicuo. La ligación es horizontal.

$\mathrm{El}$ «rāi (núm. 5) aparece en sus dos formas aislada y final, con ligadura horizontal. Cuando va a final de palabra su trazo descendente puede acentuarse, aunque sin llegar a confundirse con la 14f; en cambio, en el nombre 'Umar apenas baja de la línea de escritura y la ligación es oblicua.

Las letras del grupo sexto se han utilizado en sus formas aislada, inicial y medial, sin que pueda apreciarse diferencia de altura en sus vástagos. La forma aislada termina en un trazo vertical que desciende del último diente y se remata con un apéndice corto hacia la izquierda. La ligadura anterior es curvilínea y la posterior, en un caso, también, pero casi siempre presenta un trazado horizontal.

El séptimo grupo se encuentra representado únicamente por la «șād» inicial. Ofrece la forma de dos estrías paralelas en sentido horizontal, algo ondulada la de arriba, que se unen entre sí en ambos extremos por un trazo curvilíneo, aunque el de la izquierda no llega a apre- 
ciarse. Tampoco se percibe la ligación posterior, que parece haberse suprimido.

El grupo noveno presenta las formas inicial y medial. En la primera adopta forma de gancho, aunque el trazo curvo, en una ocasión, aparece más tendido sobre la base, mientras que en posición medial muestra su aspecto de /v/ característico. Las ligaduras son horizontales.

El grupo décimo se encuentra en posición inicial y medial. En la primera aparece montado sobre la grafía siguiente que es la $17 \mathrm{f}$, tiene forma circular y la ligación es oblicua; en la segunda tiene aspecto ovalado y las ligaduras son horizontales.

La «kāfi (núm. 11) sólo ofrece su forma final, que presenta una grafía muy parecida a la 4f, aunque más abierta. La ligación es horizontal.

La letra «lām» (núm. 12) se ha utilizado en sus formas inicial y medial. En la primera tiene la misma altura que 1a, a la que aparece unida a través de un trazo hacia la derecha en su extremo superior en la palabra al-rahmān, como ya se ha indicado. Otras veces el trazo está orientado hacia la izquierda. Su ligación es horizontal. En forma medial puede presentar una altura inferior y alternar ligaduras horizontales con oblicuas y también curvilíneas.

La «mim» (núm. 13) presenta sus grafías inicial, medial y final, y tiene forma circular, pudiendo utilizar asimismo diferentes ligaduras. $\mathrm{El}$ tipo inicial aparece encabalgado sobre la $3 \mathrm{~m}$ siguiente con ligación oblicua, en los otros casos lleva ligación horizontal. Precisamente esta grafía es una de las más esquematizadas del texto, reduciéndose a un punto inciso. El tipo medial puede presentar ligación anterior curvilínea y la posterior, a veces, sale casi desde la parte inferior de la letra. En posición final termina en un corto apéndice horizontal que sale a media altura del cuerpo de la letra.

La «nün» final (núm. 14) consiste en una estría vertical que se inicia un poco por encima de la línea de escritura y desciende, doblándose luego hacia la izquierda, en un trazo curvilíneo de longitud variable que puede rematarse formando codo hacia arriba. La ligación es horizontal.

El grupo quince aparece representado en sus posiciones medial y final, a veces también de manera muy esquemática. El cuerpo de la "hä»" medial adopta la forma de una elipse en sentido vertical, atravesada por un trazo horizontal que deja la mayor parte de ella por debajo de la línea de escritura, y lleva ligaduras horizontales. En posición final con- 
siste en un trazo vertical que puede tener la misma altura de $12 \mathrm{~m}$ -como en la palabra Allāh-, unido por su pie a otro más corto, en sentido horizontal, formando un ángulo recto que se cierra por un arco cuyo radio es igual al lado menor. A veces la grafía sólo está esbozada y se ha prescindido del trazo de cierre o del lado más corto. La ligación es horizontal.

La «wāu» (núm. 16) está presente en el texto en sus dos formas posibles, aislada y final. En la primera, el cuerpo ovalado de la letra y parte del apéndice descendente aparecen por encima de la línea de escritura; en la segunda, el trazo curvilíneo del apéndice se inicia desde la línea de escritura y tiene un desarrollo menor. La ligación es horizontal.

La "yä» final (núm. 17) ofrece dos modalidades, según vaya precedida de 10i o de otro signo. En el primer caso consiste en un trazo en forma de ángulo que se prolonga horizontalmente hacia la derecha, sobre la línea de escritura, y lleva ligaduras oblicua; en la segundo modalidad aparece por debajo de la línea de escritura, ofreciendo un perfil más abierto, en forma de codo, y con un apéndice final que se extiende hacia la derecha, paralelamente a la ligadura y a la grafía anterior.

El texto presenta asimismo, en dos ocasiones, la grafía muy simplificada del nexo «läm-alif». En ambas los caracteres aparecen unidos por su base en forma de /v/ mayúscula, con sus ápices en sentido oblicuo.

\section{e) Comentario epigráfico}

El texto de la inscripción está estructurado conforme al siguiente esquema:

Fórmula de inauguración

Identidad del difunto

Eulogia

Fecha

Eulogia

Posible alusión al Corán

Comienza con la basmala y sigue con la indicación del óbito ( $t u$ wuffiya) que precede al nombre del fallecido expresado mediante la 
kunya y un nasab de dos elementos; la habitual impetración de la misericordia divina para el difunto da paso a la consignación de la fecha con la mención del mes y del año (sana), y se prescinde, como ya se ha dicho, del día y de la feria de la semana. Con respecto a la lápida anterior, son apreciables dos innovaciones. Después de la indicación de la fecha se ha empleado una nueva eulogia, consistente en la fórmula gafara Allāh la-hu, que también hemos visto con otra disposición en la inscripción de Cazalilla y que aquí lleva un añadido cuya interpretación impide la fractura horizontal de la piedra. Igualmente ilegible resulta el inicio de lo que parece ser una alusión coránica relativa a la misión profética de Muhammad que finaliza con la tașliya.

Además de las irregularidades ortográficas de carácter más corriente, como la separación a final de línea de las letras que componen una palabra (la primera letra del nombre divino, en la línea 6), y del cambio de "alif maqșüra" por "alif tawìla", podemos observar la separación incorrecta de la particula $w a$ del numeral de las decenas, al final de la línea 4, algunas omisiones como la de "yā"» medial en rahim y del "alif maqșūra» en iḥdà, y asimismo la agregación de un «alif» final en la palabra sallama.

Debido a los desperfectos que presenta la lápida, en el numeral de las decenas que aparece al inicio de la línea 5 del texto solamente es posible apreciar la grafía de la "nūn» final precedida de lo que puede ser la repetición de $2 \mathrm{~m}$, o de $2 \mathrm{~m}$ y la terminación de $6 \mathrm{~m}$ o $6 \mathrm{i}$, lo cual reduce las posibilidades de interpretación a jamsina (cincuenta) y a sittina (sesenta). Sin embargo, el espacio tan pequeño que deja la escritura para guardar el mismo margen lateral que las otras líneas induce a considerar que la lectura correcta es sittina.

La lápida presenta un aspecto bastante descuidado, pues al escaso acondicionamiento previo de la piedra y a su naturaleza, que favorece la difuminación del texto con el paso del tiempo, se une el trazado inseguro y rudimentario de la escritura, cuyas dos últimas líneas parecen haberse realizado de forma precipitada, dando la impresión de que algunas palabras sólo están esbozadas. La disposición del texto, en términos generales, es correcta, sin que pueda destacarse una asimetría excesiva en la separación entre palabras, ni la proximidad de unas a otras induzca a errores de lectura. Por lo que se refiere al contenido, dentro de su simplificación ofrece mayor riqueza textual que la inscripción de Cazalilla, incorporando elementos habituales en otros epitafios andalu- 
síes, lo que quizá esté justificado por su elaboración más tardía, casi un siglo después.

Estos aspectos que he señalado, amén del tipo arcaico de la escritura, vienen a insistir en las que son características más generales de la epigrafía de las zonas rurales, de la que esta lápida es una buena muestra, y ponen de manifiesto el lento desarrollo de su evolución técnica en comparación con la que se realizaba en espacios urbanos.

\section{f) Comentario histórico}

Aparte de las contenidas en el epitafio, ninguna otra referencia se puede aportar sobre este Abū l-Abbās Ibn 'Abd al-Malik b. 'Umar que debió de vivir en Úbeda, en tiempos del califa al-Hakam II (961-976), donde murió y se le dio sepultura.

La utilización de la estela como material de construcción en la cerca de la ciudad no permite extraer datos del lugar de su localización, aunque es posible que originariamente se hallase en un punto situado en las inmediaciones de la muralla. La existencia de un cementerio extramuros de Ubbada (Úbeda) ${ }^{18}$-ubicación habitual, por otra parte, de las necrópolis andalusíes ${ }^{19}$ - viene confirmada por alMarrākušĩ ${ }^{20}$, quien, al recoger la biografía de un juez ubedí llamado Abū l-Ḥasan 'Alī b. Aḥmad al-Yacmurī y fallecido en el año 509/ 1115 , señala que fue enterrado a la entrada de la alcazaba (qașaba) de Úbeda.

\section{RESUMEN}

Este artículo pretende aportar nueva información para el estudio de la epigrafía árabe en España. En él se presenta la transcripción, traducción y estudio de dos epitafios funerarios inéditos, producto de hallazgos casuales, procedentes de Cazalilla y Úbeda, en la provincia de Jaén, y fechadas en el año 271/885 y en el 361/972 respectivamente. Ambas inscripciones ofrecen algunas de las

18 Sobre la Úbeda islámica, veáse Aguirre Sádaba, F. J., y Jiménez Mata, M. C., op. cit., passim; F. J. Aguirre Sádaba, op. cit., 184-186.

19 Véase Torres Balbás, L., Ciudades hispano-musulmanas, libro publicado con la colaboración de H. Terrasse, 2 t., Madrid, 1972, I, 235 y ss.

20 Dayl, V, ed. Iḥsān 'Abbās, Beirut, 1965, núm. 319, p. 158. 
características más comunes de la epigrafía en las zonas rurales, de la que constituyen una buena muestra.

\section{ABSTRACT}

This paper seeks to contribute further information for research on Arabic epigraphy in Spain. Transcription, interpretation and study of two unpublished funeral epitaphs are provided; these fortuitous discoveries are located in Cazalilla and Úbeda (Jaén province) and dated to the years 271/885 and 361/972 respectively. Both inscriptions reflect common characteristics of epigraphy in rural areas. 